This item was submitted to Loughborough's Research Repository by the author.

Items in Figshare are protected by copyright, with all rights reserved, unless otherwise indicated.

\title{
Water vapour permeability of poly(lactic acid): crystallinity and the tortuous path model
}

PLEASE CITE THE PUBLISHED VERSION

http://dx.doi.org/10.1063/1.4865168

PUBLISHER

(c) AIP Publishing LLC

VERSION

VoR (Version of Record)

LICENCE

CC BY-NC-ND 4.0

REPOSITORY RECORD

Duan, Zhouyang, and Noreen L. Thomas. 2014. "Water Vapour Permeability of Poly(lactic Acid): Crystallinity and the Tortuous Path Model". figshare. https://hdl.handle.net/2134/14329. 
This item was submitted to Loughborough's Institutional Repository (https://dspace.lboro.ac.uk/) by the author and is made available under the following Creative Commons Licence conditions.

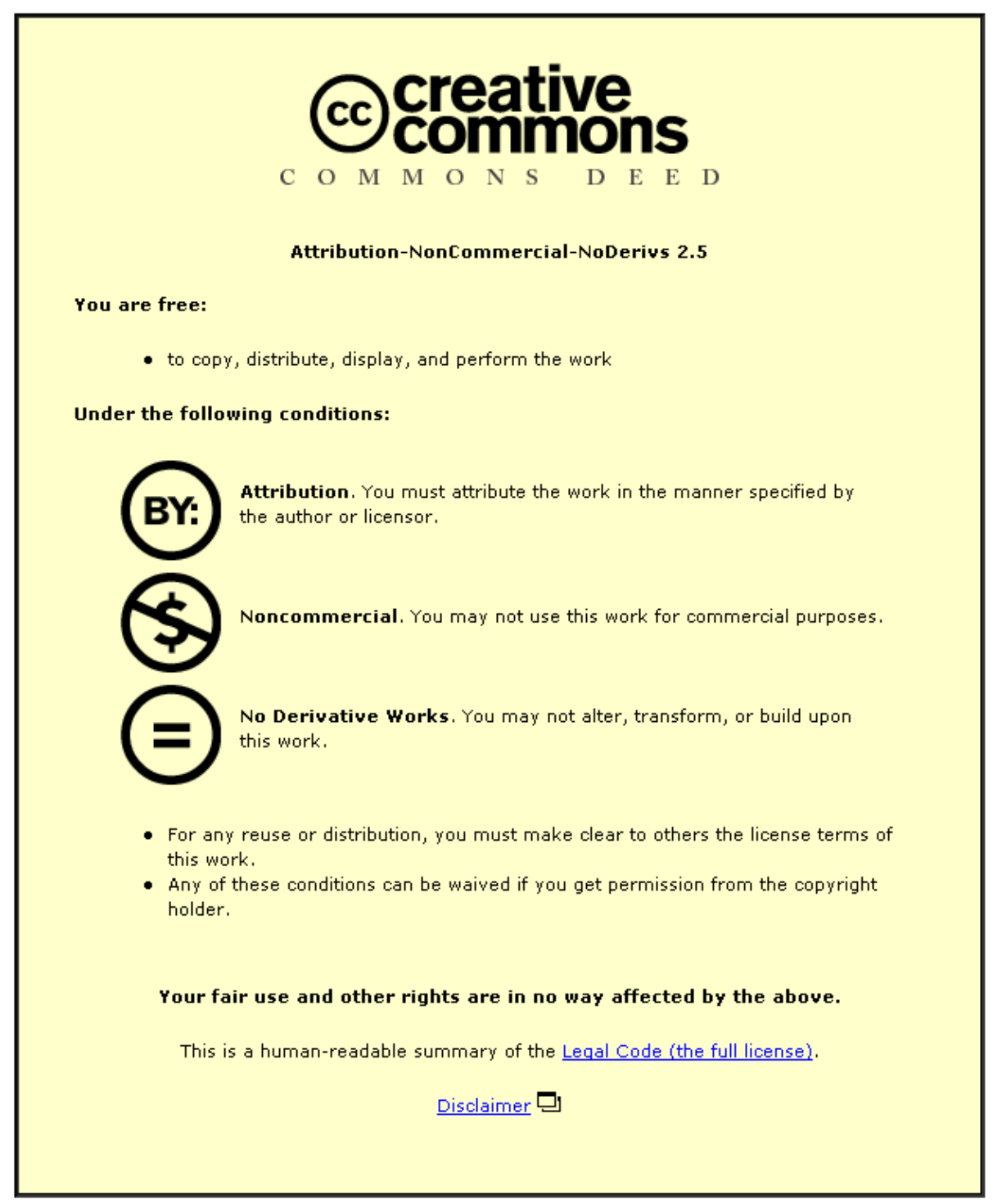

For the full text of this licence, please go to: http://creativecommons.org/licenses/by-nc-nd/2.5/ 


\title{
Water vapour permeability of poly(lactic acid): Crystallinity and the tortuous path model
}

\author{
Z. Duan and N. L. Thomas ${ }^{\text {a) }}$ \\ Department of Materials, Loughborough University, Loughborough LE11 3 TU, United Kingdom
}

(Received 3 December 2013; accepted 28 January 2014; published online 11 February 2014)

\begin{abstract}
The water vapour transmission rates (WVTR) through samples of polylactic acid of different crystallinities have been measured. Three different grades of commercial poly(lactic acid) (PLA) were used with different ratios of L-lactide and D-lactide to give a range of crystallinities from $0 \%$ to $50 \%$. Sheets of PLA were prepared by melt compounding followed by compression moulding and annealing at different temperatures and for different times to give the range of crystallinities required. Crystallinity was measured by differential scanning calorimetry and the morphology of the samples was observed under crossed polars in a transmitted light microscope. Water vapour transmission rates through the films were measured at $38{ }^{\circ} \mathrm{C}$ and at a relative humidity of $90 \%$. It was found that the measured values of WVTR decreased linearly with increasing crystallinity of the PLA from $0 \%$ to $50 \%$. The results are discussed in terms of the effect of crystallinity on solubility and shown to fit the "Tortuous Path Model." The model was also successfully used to explain published data on water permeability of polyethylene terephthalate. (C) 2014 AIP Publishing LLC.
\end{abstract}

[http://dx.doi.org/10.1063/1.4865168]

\section{INTRODUCTION}

In recent years, there has been growing concern about the disposal of plastic waste and the need to find alternatives to landfill. This has led to increasing interest in biodegradable polymers. Coupled with this is the requirement to find replacements for fossil fuel feedstocks, and hence the focus on polymers that are derived from renewable resources, such as plant-based feedstocks. One of the most commercially successful polymers that is both bio-derived and bio-degradable is poly(lactic acid) (PLA).

Lactic acid, the monomer for PLA, is produced by carbohydrate fermentation of feedstocks, such as maize sugar or corn starch. ${ }^{1,2}$ There are a number of methods for producing high molecular weight PLA but the method that is the most successful, and is used commercially, is by ring-opening polymerisation of the lactide, which is a cyclic dimer that consists of two lactic acid molecules. ${ }^{3,4}$ Hence PLA is also referred to as poly(lactide). Because of the asymmetric carbon atom in lactic acid, it occurs in two optically active configurations ( $\mathrm{L}$ and $\mathrm{D}$ ). These two configurations can form three different lactides: L-lactide (a dimer of L-lactic acid), D-lactide (a dimer of D-lactic acid), and meso-lactide (a dimer of L- and D-lactic acid). The crystallisability of the polymer is governed by its content of L-, D-, and meso- lactide: the more optically pure polymers have higher crystallinities due to higher chain symmetry. PLA resin containing $50 \%-93 \%$ of L-lactic acid is amorphous, due to the imperfections introduced by the D-lactic acid. ${ }^{3}$ However, PLA with more than $93 \%$ of L-lactic acid is semi-crystalline.

A number of studies have been carried out on the crystallisation behaviour of PLA. ${ }^{4-7}$ Tsuji and Ikada $^{4}$ have shown

\footnotetext{
a) Author to whom correspondence should be addressed. Electronic mail: N.L.Thomas@lboro.ac.uk.
}

how processing procedure, annealing temperature, and time affect the degree of crystallinity, spherulite size, morphology, and melting point. Yasuniwa et al. ${ }^{5}$ have investigated the crystallisation kinetics and morphology of poly(L-lactic acid) by thermal analysis, optical microscopy, and X-Ray diffraction. They reported a discrete change in crystallisation behaviour at $113^{\circ} \mathrm{C}$ with different crystalline forms being developed above and below this temperature. Pan et al. ${ }^{6,7}$ reported that the disordered $\alpha^{\prime}$ crystalline form, which forms during processing or annealing at lower temperatures, transforms into the more ordered $\alpha$ form. These authors also found that the temperature at which the $\alpha^{\prime}-\alpha$ phase transition occurs depends on the molecular weight of the polymer; being at higher temperature in higher molecular weight polymer.

It is well known that crystallinity affects the barrier properties of polymers because crystallites act essentially as inert fillers that are impermeable to both gas and liquid penetrants. Hence it is expected that permeability should decrease as crystallinity increases. An early explanation of the effect of crystallinity is the classic two-phase model of Michaels et al. ${ }^{8,9}$ These authors studied diffusion of helium, oxygen, nitrogen, argon, carbon dioxide, and methane in glassy and rubbery poly(ethylene terephthalate) (PET) in the temperature range 25 to $130{ }^{\circ} \mathrm{C}$. According to their results, below the glass transition temperature, diffusion is impeded purely geometrically by the presence of the crystallites, and the extent of impedance is inversely proportional to the amorphous volume fraction.

Drieskens et al. ${ }^{10}$ have investigated the effect of crystallinity on the oxygen permeability of poly(lactic acid). Crystallisation of PLA caused a reduction in oxygen permeability but this was not in linear proportion with the decrease in amorphous volume. Diffusivity was found to decrease with increasing crystallinity but solubility of oxygen in PLA showed an unexpected increase. The results were discussed in terms of the presence of a constrained or rigid amorphous 
fraction with lower density that gave rise to the observed effects on the gaseous solubility coefficient.

The water vapour permeability of compostable and biodegradable polymers would be expected to be relatively high given that they are polar polymers with relatively high values of water vapour solubility. Shogren ${ }^{11}$ has reported the water vapour transmission rates (WVTR) of a number of biodegradable polymers and showed that the results correlated with water solubility, crystallinity, and the effect of the glass transition temperature $\left(\mathrm{T}_{\mathrm{g}}\right)$.

Siparsky and co-workers ${ }^{12}$ have investigated water transport in PLA and some PLA copolymers and blends. PLA films were prepared with different degrees of crystallinity ranging up to $46 \%$. It was reported that the degree of crystallinity had little influence on the measured permeability parameters and that the permeability process was best described by a "water cluster" model for hydrophobic polymers. These authors also investigated hydrolysis in PLA films at $90 \%$ relative humidity and at temperatures between 20 and $50{ }^{\circ} \mathrm{C}$. They showed that under these conditions hydrolysis in PLA films is a very slow process compared with water vapour diffusion.

The effects of molecular characteristics and crystallinity on the water vapour permeability of poly(lactides) has been researched by Tsuji et al. ${ }^{13,14}$ It was reported that WVTR decreased monotonically with increasing crystallinity up to $20 \%$ and levelled off at $30 \%$ due to the higher resistance of "restricted" amorphous regions. Another study by Cocca et al. ${ }^{15}$ has reported water vapour permeability of poly(1-lactide) with crystallinity varying between $33 \%$ and $45 \%$. There was found to be a constant value of permeability from $33 \%$ to $39 \%$ crystallinity but a sudden drop at $39 \%-40 \%$, which was attributed to a different ratio of crystalline polymorphs in the structure.

The aim of this paper is to carry out a detailed study of how crystallinity (in the range from 0 to $50 \%$ ) affects water vapour permeation through PLA films and to quantitatively model the results. A tortuosity model is applied to give a theoretical prediction of experimental results. This model was first devised by Nielsen ${ }^{16}$ to describe the permeability of gases and liquids through filled polymer systems. It has recently been used successfully to model the water vapour permeability through PLA nanocomposites. ${ }^{17}$ In the current study, PLA films with crystallinities ranging from $0 \%$ up to $50 \%$ are prepared by melt compounding followed by compression moulding with different thermal treatments to give the range of crystallinities required. The morphology, thermal properties, and water vapour transmission rates of these samples are investigated. The results are then interpreted in terms of the tortuous path model. Furthermore, existing data from the literature on polyethylene terephthalate are reinterpreted in the light of these results and also shown to fit a tortuosity model.

\section{EXPERIMENTAL}

\section{Materials}

Three grades of polylactide (PLA) polymer Ingeo $^{\mathrm{TM}}$ 4060D, 4042D and 4032D) were supplied by Natureworks
LLC (Minetonka, MN, USA). 4060D is an amorphous polymer with an L-lactide content of around 88 weight $\%$ and with a glass transition temperature $\left(\mathrm{T}_{\mathrm{g}}\right)$ of $55-60^{\circ} \mathrm{C}$. Both 4042D and 4032D are crystallisable grades of PLA with L-lactide contents of about 95.75 and 98.6 weight $\%$, respectively. The melting point range is $160-180^{\circ} \mathrm{C}$.

\section{Preparation and processing of the PLA sheets}

Before processing, the PLA granules were dried at $60^{\circ} \mathrm{C}$ for $24 \mathrm{~h}$ in a vacuum oven to remove excess moisture.

The PLA was then melt blended in a counter-rotating mixer (Haake Rheomix OS) to promote dispersive and distributive mixing. The sample weight added to the mixer was $58 \mathrm{~g}$ and mixing was carried out at $170^{\circ} \mathrm{C}$ for $10 \mathrm{~min}$ with a constant rotor speed of $60 \mathrm{rpm}$.

PLA sheets for water vapour permeability measurements were then prepared by compression moulding in a 20 ton hydraulic press. The materials were hot pressed at $180^{\circ} \mathrm{C}$ and the melt compressed for $5 \mathrm{~min}$ at 14 tons pressure.

The cooling protocol adopted was varied depending on the grade of PLA and the range of crystallinities required. The different regimes adopted are described below.

- Quenching: PLA sheets were quenched between watercooled plates at a pressure of 5 tons for $3 \mathrm{~min}$.

- Annealing: the sheets were annealed at either $100^{\circ} \mathrm{C}$, $115^{\circ} \mathrm{C}$, or $130^{\circ} \mathrm{C}$ at a pressure of 5 tons for between 5 and 25 min depending on the crystallinity required. They were then cooled to room temperature.

- Slow cooling: the sheets were cooled to $140^{\circ} \mathrm{C}$ and then allowed to cool slowly to $95^{\circ} \mathrm{C}$ over a period of an hour at a pressure of 5 tons.

In this way, 25 samples were produced with crystallinities varying between $0 \%$ and $52 \%$. The average thickness of the samples was $0.6 \mathrm{~mm}$.

\section{Characterisation techniques}

\section{Differential scanning calorimetry (DSC)}

The glass transition temperature $\left(\mathrm{T}_{\mathrm{g}}\right)$, cold crystallisation, melting behaviour, and crystallinity of the PLA samples were investigated using DSC. Measurements were performed using a DSC Q200 (TA Instruments, USA) fitted with an auto-sampler and mechanical cooler. Samples of approximately $10 \sim 15 \mathrm{mg}$ in mass were sealed in aluminium pans and loaded into the chamber. The samples were heated from $20^{\circ} \mathrm{C}$ to $200^{\circ} \mathrm{C}$ in a nitrogen atmosphere at a rate of $10^{\circ} \mathrm{C} / \mathrm{min}$. Data were analysed using the TA universal analysis software package.

The amount of overall crystallinity was calculated using Eq. (1)

$$
\% \text { Crystallinity }=\left[\frac{\Delta H_{m}-\Delta H_{c}}{93.1}\right] * 100 \%
$$

In Eq. (1), $\Delta \mathrm{H}_{\mathrm{m}}(\mathrm{j} / \mathrm{g})$ is the measured heat of fusion (melting enthalpy), $\Delta \mathrm{H}_{\mathrm{c}}(\mathrm{j} / \mathrm{g})$ is the enthalpy of cold crystallisation, 
and $93.1(\mathrm{j} / \mathrm{g})$ is the enthalpy of fusion for $100 \%$ crystalline PLA.

\section{Optical microscopy}

Optical microscopy was used to study the crystalline morphology of the PLA sheets. Samples were observed between crossed polars in a Leica ${ }^{\circledR}$ DM LM binocular transmitted light microscope. The spherulitic structure was observed at room temperature and then the samples were heated to $200{ }^{\circ} \mathrm{C}$ using the hot stage facility at a rate of $10^{\circ} \mathrm{C} / \mathrm{min}$. This allowed observation of the cold crystallisation and melting behaviours.

\section{Water vapour permeability measurements}

WVTR through the various PLA sheets were measured using a MOCON (Modern Controls Inc., USA) PermatranW@398 operated at $38^{\circ} \mathrm{C}$ and a relative humidity of $90 \%$. Values of WVTR reported in this paper are normalised to allow for the effect of the sample thickness $(\mathrm{t})$. Hence water transmission rates as measured are multiplied by $(\mathrm{t} / 25 \mu \mathrm{m})$ and are reported in units of g.mil $/ \mathrm{m}^{2} / \mathrm{day}$.

\section{RESULTS AND DISCUSSION}

\section{Differential scanning calorimetry}

Samples were taken from the processed PLA sheets to examine the thermal properties of the polymer and particularly to measure the degree of crystallinity. The samples were taken from the perimeter of each sheet and the central portion used for subsequent permeability measurements.

Figure 1 shows the DSC first heating scan for PLA grade 4060D. The step change that occurs at $55^{\circ} \mathrm{C}$ relates to the glass transition temperature $\left(\mathrm{T}_{\mathrm{g}}\right)$ of the polymer. The peak just after the step change corresponds to an enthalpic relaxation peak, associated with relaxation of non-equilibrium structure. There is no cold crystallisation temperature $\left(\mathrm{T}_{\mathrm{c}}\right)$ and neither is there any melting point $\left(\mathrm{T}_{\mathrm{m}}\right)$, thus confirming the amorphous nature of the polymer.
The second grade of PLA, 4042D, will crystallise, but very slowly. Figure 2 shows the DSC trace (first heating scan) sampled from a slowly cooled sheet of PLA 4042D. The glass transition temperature $\left(\mathrm{T}_{\mathrm{g}}\right)$ is $60^{\circ} \mathrm{C}$. The exothermic peak at $120^{\circ} \mathrm{C}$ corresponds to cold crystallisation, i.e., crystallisation on heating above the $\mathrm{T}_{\mathrm{g}}$. The melting point is at $152^{\circ} \mathrm{C}$; and for this sample, the crystallinity, as calculated from Eq. (1), is $4.4 \%$.

Figure 3 shows the DSC trace for the crystallisable grade of PLA, 4032D, sampled from a sheet that had been annealed at $100^{\circ} \mathrm{C}$ for $18 \mathrm{~min}$. The glass transition temperature is at $57^{\circ} \mathrm{C}$ and the cold crystallisation peak is around $114^{\circ} \mathrm{C}$. The melting peak is at a temperature of $170{ }^{\circ} \mathrm{C}$. There is a small peak at about $160^{\circ} \mathrm{C}$ merging into the main melting peak. The lower peak corresponds to melting of the $\alpha^{\prime}$ phase, which is the disordered crystalline form, whereas the main peak corresponds to melting of the $\alpha$ phase, which is the ordered crystalline form. ${ }^{6,7}$ The crystallinity of this sample is $29.6 \%$.

Annealing the PLA sheets at the cold crystallisation temperature $\left(115^{\circ} \mathrm{C}\right)$ gave high levels of crystallinity. For example, Figure 4 shows the DSC trace taken from a sheet of PLA 4032D that had been annealed at $115^{\circ} \mathrm{C}$ for $25 \mathrm{~min}$. There is virtually no cold crystallisation peak and a very large melting peak at $167^{\circ} \mathrm{C}$, showing that the sample is highly crystalline. The crystallinity, as calculated from Eq. (1), is $44 \%$.

Table I summarises the various different annealing or cooling regimes used during processing and the crystallinities of the PLA sheets produced, as measured by DSC. It is seen that crystallinity ranged from $0 \%$ up to $51 \%$. The water vapour transmission rate through each of these sheets was measured.

\section{Optical microscopy}

The crystalline morphology of a PLA sheet produced by annealing $4032 \mathrm{D}$ at $100^{\circ} \mathrm{C}$ for $18 \mathrm{~min}$ was investigated in the hot stage optical microscope between crossed polars.

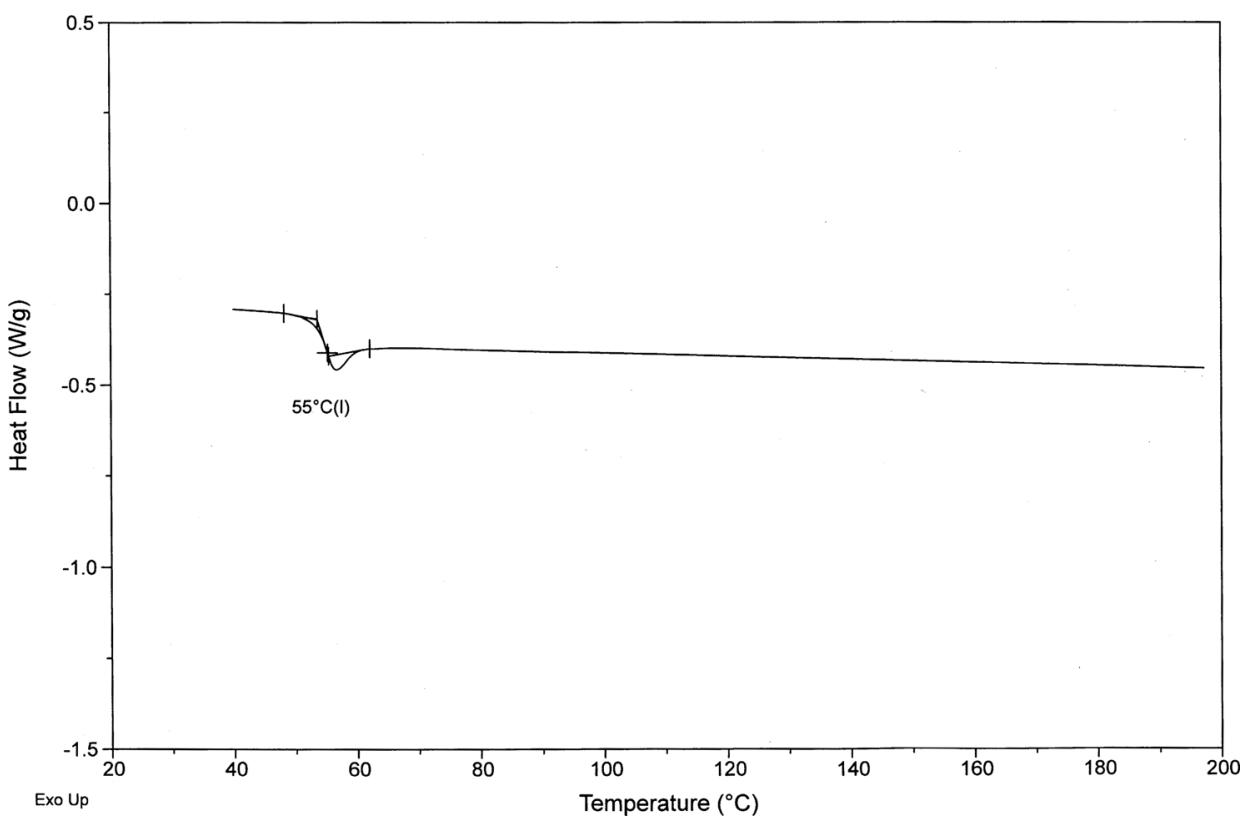

FIG. 1. DSC Heating Scan of PLA 4060D. 


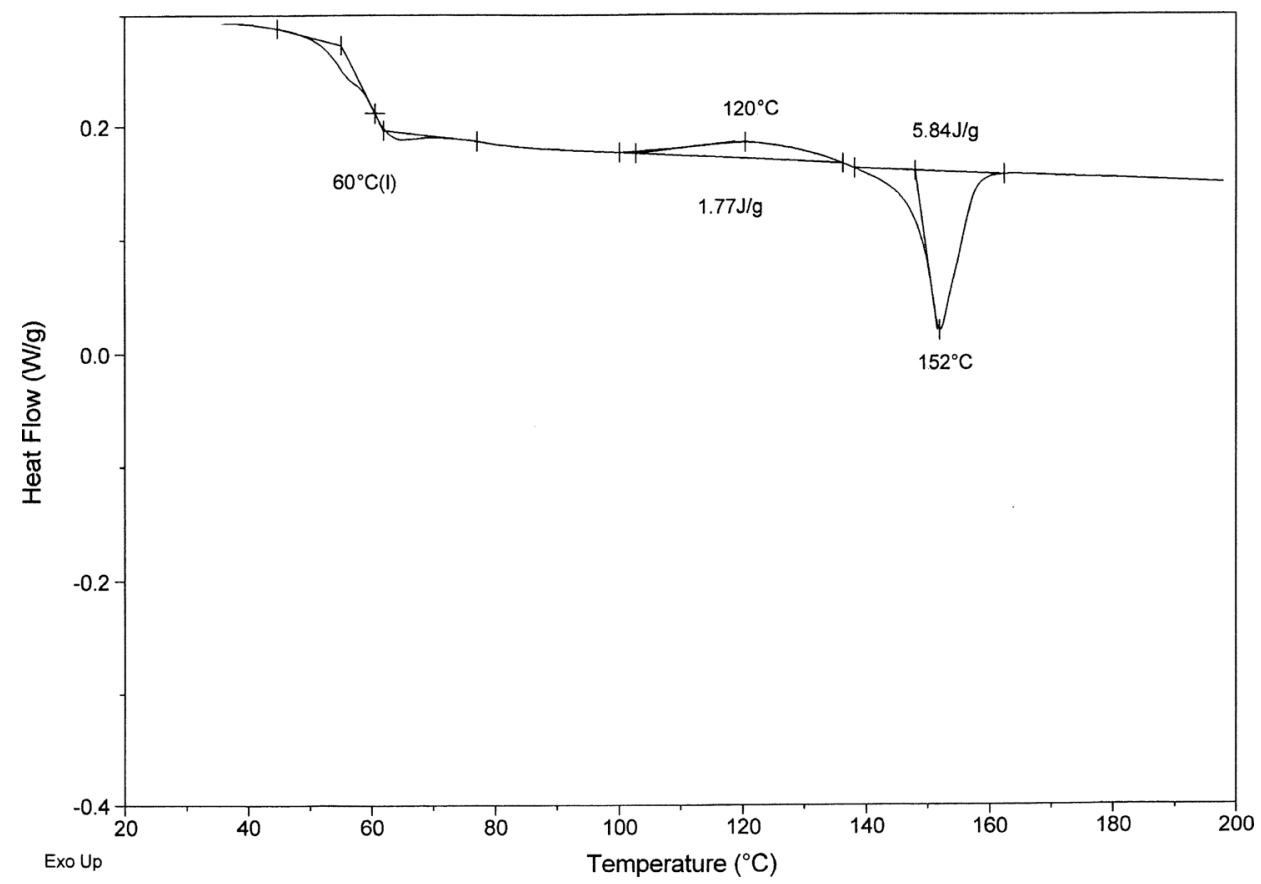

FIG. 2. DSC Heating Scan of PLA 4042D.

Figure 5 shows a series of micrographs taken at different temperatures when the sample was heated at $10^{\circ} \mathrm{C}$ per minute. The changes in morphology can be interpreted in relation to the DSC scan shown in Figure 3. It is seen in the image taken at $40^{\circ} \mathrm{C}$ that two types of crystals exist: some coarser spherulites in a background of tiny crystallites. Cold crystallisation is found to occur at around $114^{\circ} \mathrm{C}$ from the DSC scan, so when the sample reaches $120^{\circ} \mathrm{C}$, cold crystallisation has already been taking place. In the micrograph, it is seen that the number and size of the larger spherulites has increased. At $158{ }^{\circ} \mathrm{C}$, it is seen that the larger spherulites have grown. As the melting point is approached, it is found at $167^{\circ} \mathrm{C}$ that the area of tiny crystallites has reduced and become blurred, whereas the larger spherulites have not obviously changed. This corresponds to the melting of the $\alpha^{\prime}$ phase, i.e., the disordered crystalline form. At $169^{\circ} \mathrm{C}$, the whole image becomes dark, indicating that melting is occurring.

Figure 6 shows what happens when PLA 4032D that has already been melted is held at $100^{\circ} \mathrm{C}$. Crystallites start to nucleate after a minute. After $9 \mathrm{~min}$, tiny crystallites are covering the whole area. These continue to grow and coarsen as the sample is annealed for a longer time.

A specimen taken from a slow cooled PLA 4032D sheet is shown in Figure 7. This sample was cooled over a wide temperature range for a long time $(1 \mathrm{~h})$ and it is seen that some very large spherulites $(100 \mu \mathrm{m}$ diameter) have grown. According to Yasuniwa et al. ${ }^{5}$ these big spherulites form at

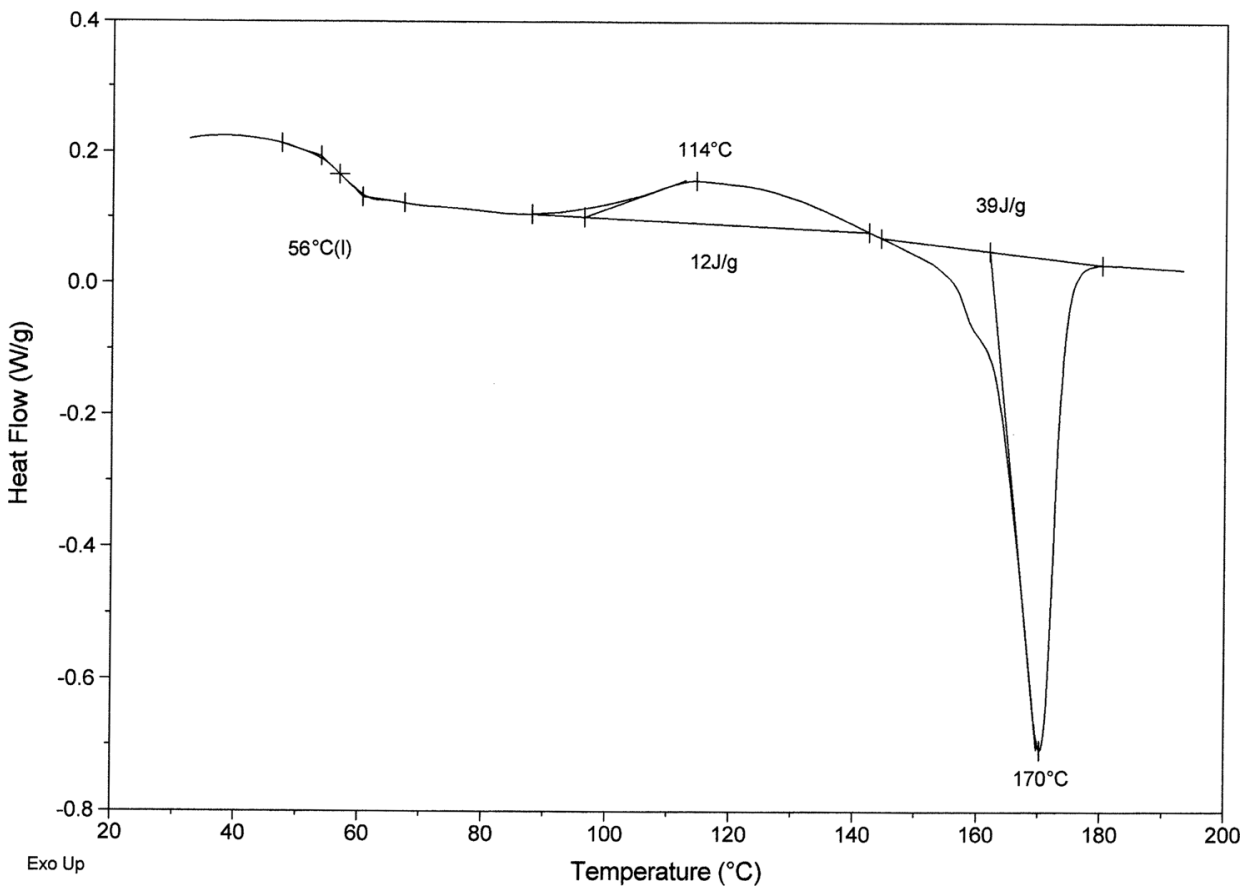

FIG. 3. DSC Heating Scan of PLA 4032D annealed at $100^{\circ} \mathrm{C}$ for $18 \mathrm{~min}$. 


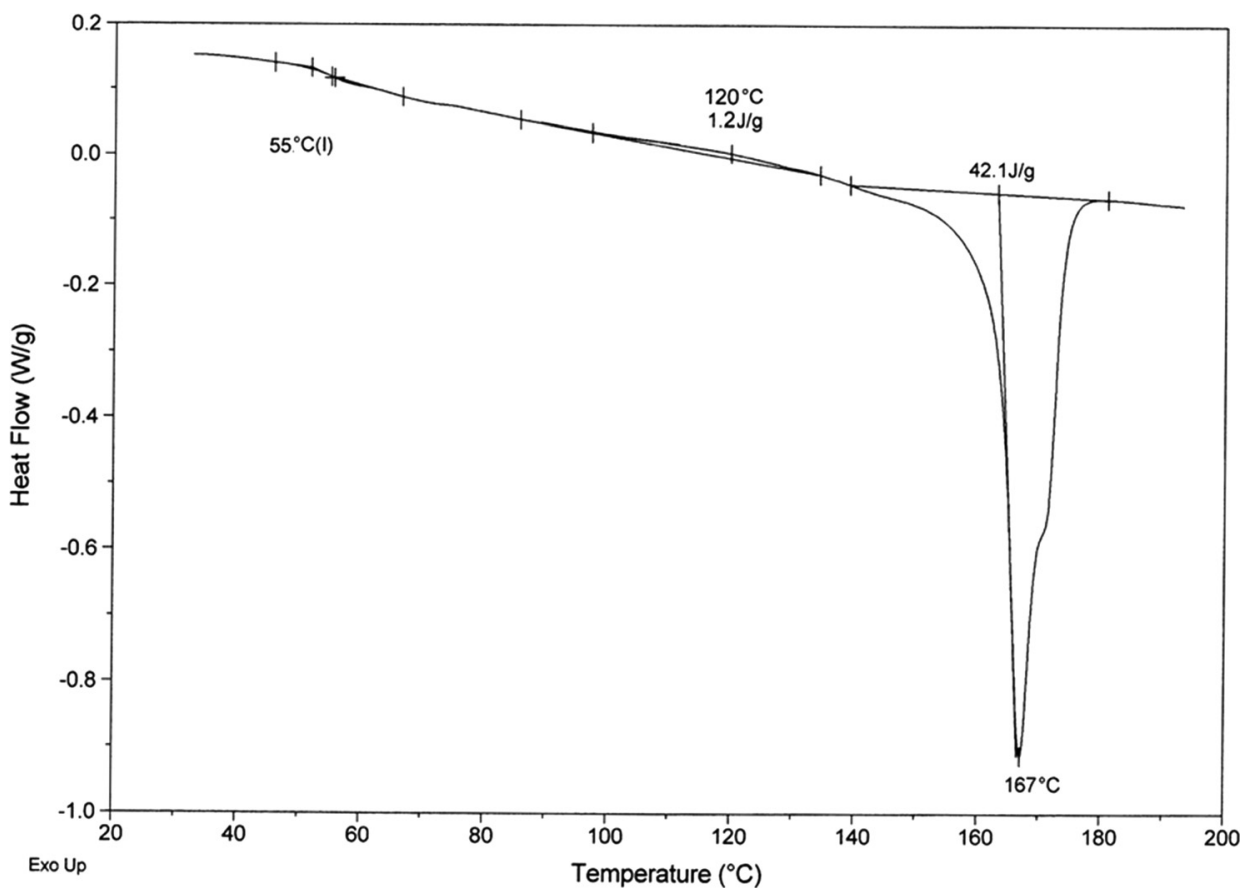

FIG. 4. DSC Heating Scan of PLA 4032D annealed at $115^{\circ} \mathrm{C}$ for $25 \mathrm{~min}$.

high temperature, with a slow nucleation rate. As the temperature decreased slowly, many small crystallites formed and filled the gap between the big spherulites. The double peak that appears in the melting endotherm on the DSC plot (Figure 4) also indicates that at least two different types of spherulite exist. In this case, the secondary peak is at a higher temperature than the main peak, implying that this is due to the melting of the large spherulites.

\section{Water vapour permeability measurements}

\section{Interpretation by a linear model}

Results from measurements of water vapour transmission rates are plotted as a function of crystallinity in Figure 8 . It is seen that the measured values of WVTR decrease linearly with increasing crystallinity right up to $50 \%$ crystallinity. The data show a good fit to the linear trend line with a regression coefficient, $\mathrm{R}^{2}$, of 0.96 .

This result can be readily explained in terms of the effect of crystallinity on the solubility of water vapour in polymers. According to the classic two-phase model of Michaels et al., ${ }^{8,9}$ water will not be soluble in the crystalline regions and so the solubility coefficient $(\mathrm{S})$ of a semi-crystalline

TABLE I. Crystallinities Obtained from Different Cooling and Annealing Regimes.

\begin{tabular}{lcc}
\hline \hline Polymer & Processing procedure & $\%$ Crystallinity \\
\hline PLA 4060D & Quenched or slow cooled & 0 \\
PLA 4042D & Quenched & 0.8 \\
PLA 4042D & Slow cooled & $1.7,2.1,3.0,4.4$ \\
PLA 4032D & Quenched & $5.4,7.2,12$ \\
PLA 4032D & Annealed at $130^{\circ} \mathrm{C}$ for 5 min & $11,12,13,13,17,19$ \\
PLA 4032D & Annealed at $100^{\circ} \mathrm{C}$ for $18 \mathrm{~min}$ & 30,35 \\
PLA 4032D & Annealed at $115^{\circ} \mathrm{C}$ for $25 \mathrm{~min}$ & $35,42,43,44$ \\
PLA 4032D & Slow cooled & $43,49,51$ \\
\hline \hline
\end{tabular}

polymer is equal to the solubility coefficient of the amorphous fraction. This is given by

$$
S=S_{0}\left(1-X_{C}\right)
$$

where $S_{0}$ is the solubility coefficient of the amorphous polymer and $X_{c}$ is the fractional degree of crystallinity. Given that permeability is the product of diffusivity and solubility, then a linear relationship can be explained. This is particularly relevant to water permeability because the permeability of polymers to water is dominated by the solubility of water in the polymer, ${ }^{18,19}$ whereas gaseous permeation in polymers is usually dominated by the diffusivity term.

No other study has reported a detailed range of data from $0 \%$ up to $50 \%$ crystallinity. Work by Tsuji et al. ${ }^{13}$ has investigated the effect of crystallinity on water permeability of PLA and found a monotonic decrease with increasing crystallinity from $0 \%$ to $20 \%$, which then levelled off. In a recent publication, Tsuji and Tsuruno ${ }^{14}$ reported further studies of water vapour permeability of poly(L-lactic acid)/poly(D-lactic acid) blend films in which crystallinity ranged from $0 \%$ to $30 \%$. The films were produced by solution casting and WVTR measurements were carried out at $25^{\circ} \mathrm{C}$, using a gravimetric method with anhydrous calcium chloride in a sealed cup. The 10 data points from this study can be fitted on exactly the same straight line as our data in Figure 8, which is a gratifying, if somewhat surprising, result-given that our measurements were carried out at $38^{\circ} \mathrm{C}$ and those of Tsuji at $25^{\circ} \mathrm{C}$. As discussed below, there can be two explanations for this: either there is no effect of temperature on water vapour permeability in PLA in the temperature range $25-40{ }^{\circ} \mathrm{C}$ or it is due to the different methods of film preparation. Regarding the first point, Auras et al. ${ }^{20}$ have reported a decrease in water vapour permeability coefficient with increasing temperature for two different grades of PLA. Regarding the second point, Rhim et al. ${ }^{21}$ have reported differences in permeability measurements for films 


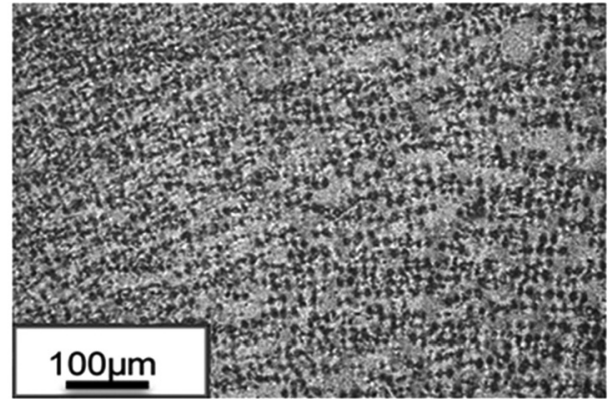

(a)

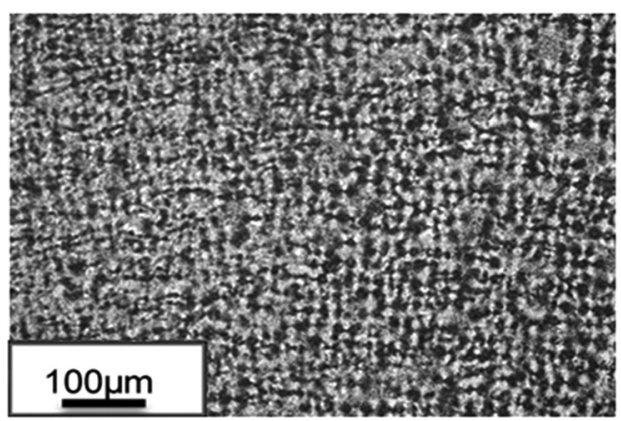

(c)
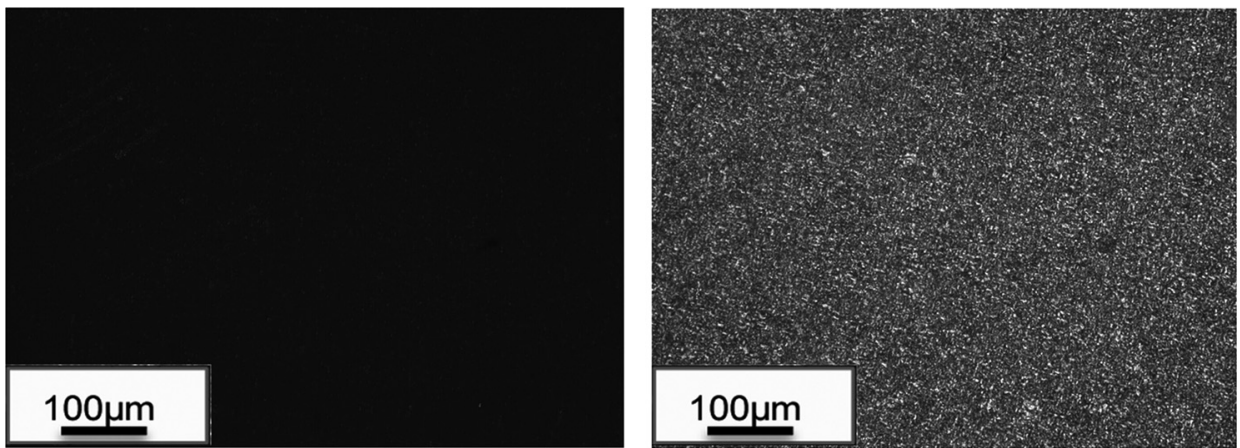

FIG. 5. PLA 4032D annealed at $100^{\circ} \mathrm{C}$ for $18 \mathrm{~min}$ then viewed in hot stage polarised optical microscope at (a) $40^{\circ} \mathrm{C}$, (b) $120^{\circ} \mathrm{C}$, (c) $158^{\circ} \mathrm{C}$, and (d) $167^{\circ} \mathrm{C}$.
FIG. 6. PLA $4032 \mathrm{D}$ held at $100^{\circ} \mathrm{C}$ after being melted in the hot stage polarised optical microscope (left) after $1 \mathrm{~min}$ and (right) after $9 \mathrm{~min}$. produced by thermo-compression and solvent casting: the solvent cast films had a significantly higher value of WVTR than the compression moulded films.

Returning to the linear relationship found in Figure 8, the equation of the trend line is given by Eq. (3)

$$
W V T R=207\left(1-1.29 X_{C}\right) .
$$

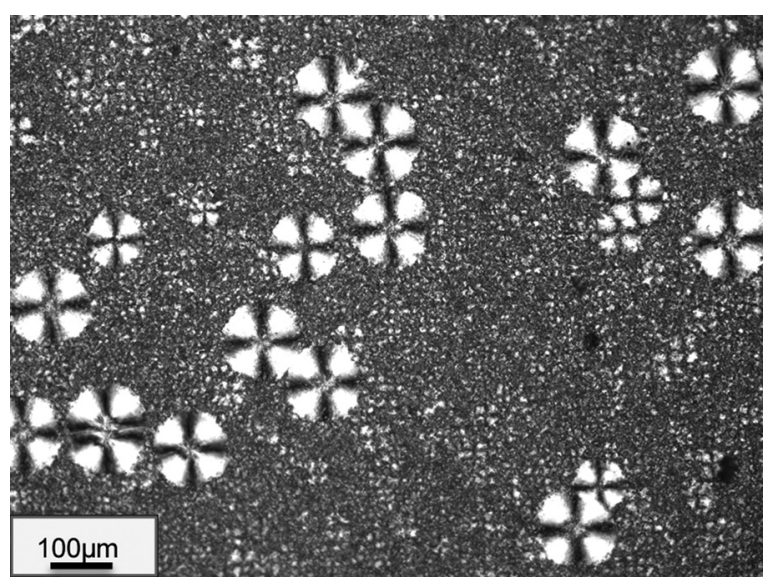

FIG. 7. Polarised optical micrograph of a slow cooled PLA 4032D sample.
While it is clearly unwise to extrapolate the trend any further than the experimental data, it is evident from the equation that the linear relationship predicts zero permeability when the crystallinity reaches about $78 \%$. This seems unlikely, which leads to the conclusion that the data are better interpreted in terms of the "tortuous path" model (see section below), which predicts that permeability does not drop to zero until crystallinity reaches $100 \%$.

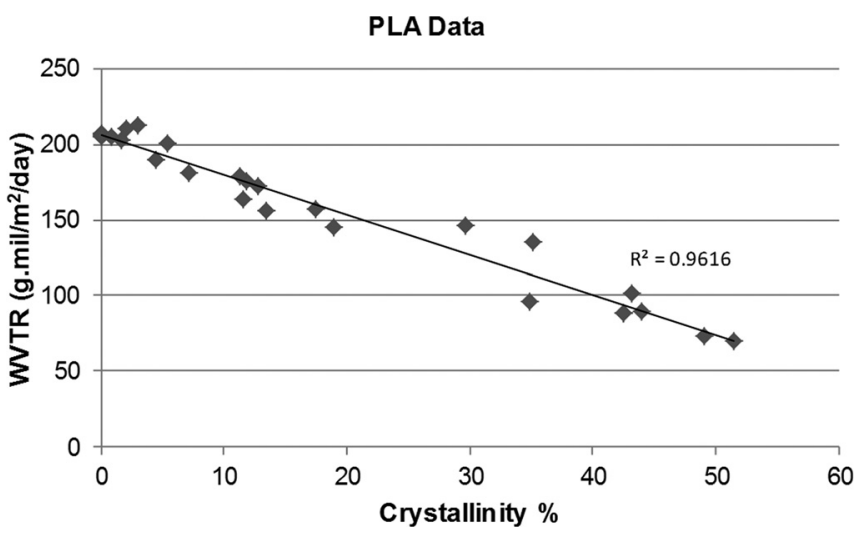

FIG. 8. Water Vapour Transmission Rate at $38^{\circ} \mathrm{C}$ as a Function of Crystallinity. 
There is, however, an explanation in the literature for why permeability might drop to zero at crystallinity values of less than $100 \%$. It is that the crystalline phase reduces the polymer chain mobility in the amorphous phase, giving rise to constrained or restricted regions, which have reduced water solubility and therefore reduced permeability. The concept of constrained amorphous regions has been mentioned by a number of authors in discussions of the effect of crystallinity on both gaseous and aqueous permeability in PLA $^{10,14}$ and generally in other polymers. ${ }^{8,9}$

Finally, while discussing the linear model and the effects of solubility, it should be mentioned that Siparsky et al. ${ }^{12}$ have reported that the water solubility parameter for PLA at temperatures around $40^{\circ} \mathrm{C}$ is constant regardless of the degree of crystallinity of the polymer. This somewhat surprising effect was attributed to water clustering in the PLA system, which would affect the measured values of solubility.

\section{Interpretation by a tortuous path model}

Another explanation is that the data can be modelled by the "tortuous path" equation. This model was developed by Nielsen ${ }^{16}$ to explain permeability in filled polymer systems. Filler particles are impermeable and create a more tortuous diffusion path for gas or water molecules. The efficacy of the filler in reducing permeation depends on its concentration, orientation, and aspect ratio. Assuming that the filler platelets are aligned perpendicularly to the diffusion direction, the Nielsen model is given by Eq. (4) below

$$
\frac{P_{c}}{P_{m}}=\frac{1-V_{f}}{1+\frac{L}{2 D} \cdot V_{f}},
$$

where $\mathrm{P}_{c}$ is the permeability of the polymer composite, $\mathrm{P}_{\mathrm{m}}$ is the permeability of the unfilled polymer matrix, $V_{f}$ is the volume fraction of filler, and L/D is the aspect ratio (length/thickness) of the filler.

This model has been used to account for the observed improvements in barrier properties (to both water vapour and gases) of polymer nanocomposites. For example, Choudalakis and Gotsis ${ }^{22}$ have reviewed a large number of studies on the gaseous permeability of polymer nanocomposites and discussed a number of models proposed to predict permeability. It seems that the relative permeability is independent of both the polymer type and the species of gas diffusing through the matrix. It was concluded that assuming that the aspect ratio and orientation of the nanofiller particles are known, then the tortuous path model, which is the simplest, is reasonably successful in predicting permeability. More specifically, the Nielsen equation has been recently used to successfully model the water vapour permeability through PLA nanocomposite films in which the aspect ratio of the nanoclay filler was measured as $50 .{ }^{17}$

In the case of crystallinity, it must be assumed that the spherulites are impermeable filler particles with an aspect ratio of 1 . With this assumption, the Nielsen equation can be written very simply as in Eq. (5) in which $P$ is the permeability of the semi-crystalline polymer, $\mathrm{P}_{0}$ is the permeability of the amorphous polymer, and $\mathrm{X}_{\mathrm{c}}$ is the fractional degree of crystallinity.

$$
\frac{P}{P_{0}}=\frac{1-X_{c}}{1+\frac{X_{c}}{2}} .
$$

Equation (5) has been fitted to the experimental data as shown in Figure 9. There is found to be a good fit with a regression coefficient, $R^{2}$, of 0.95 . This is an elegant model that predicts that the water vapour permeability drops to zero at $100 \%$ crystallinity.

Given that the tortuous path model gives the best explanation of the effect of crystallinity on water vapour transmission data in PLA films, the question then arises as to whether it is applicable to other polymers.

\section{Interpretation of data on poly(ethylene terephthalate)}

PET is another polymer that can be thermally treated to produce a range of crystallinities from zero up to $40 \%$ or $50 \%$. One of the earliest studies on the effect of crystallinity on the moisture permeability of PET was carried out by Lasoski and Cobbs. ${ }^{23}$ They prepared amorphous PET film by extrusion and quenching. Polymer of increased crystallinity was then prepared by annealing samples of the amorphous film (restrained in frames) at temperatures from 100 to $200^{\circ} \mathrm{C}$ for various times. The crystallinity of the films was determined by density measurements. Water vapour permeability was measured by the "cup method" at $39.5^{\circ} \mathrm{C}$.

Data showing the relationship between water permeability and crystallinity from the paper by Lasoski and Cobbs ${ }^{23}$ are plotted in Figure 10. Here, it can be seen that the data give a good fit to a linear model with a regression coefficient, $\mathrm{R}^{2}$, of 0.97 . However, the data do not fit the tortuous path model of Eq. (5). In their paper, Lasoski and Cobbs concluded that the best fit of their data was to the square of the amorphous volume fraction, but there appears to be no theoretical justification for this.

The key to interpreting the data of Lasoski and Cobbs comes in a publication by Polyakova et al. ${ }^{24}$ who investigated the effect of crystallisation from the glassy state (cold crystallisation) on the oxygen barrier properties of

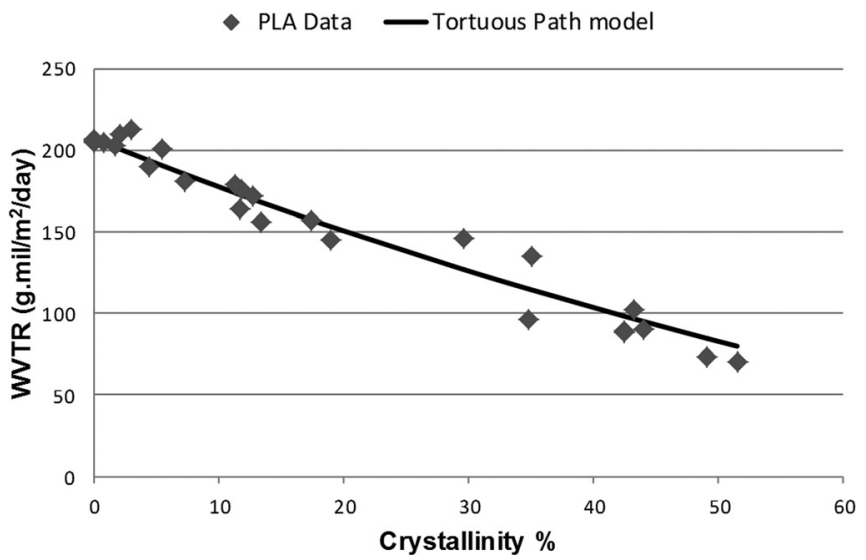

FIG. 9. Water Vapour Transmission Data fitted to the "Tortuous Path" Model. 


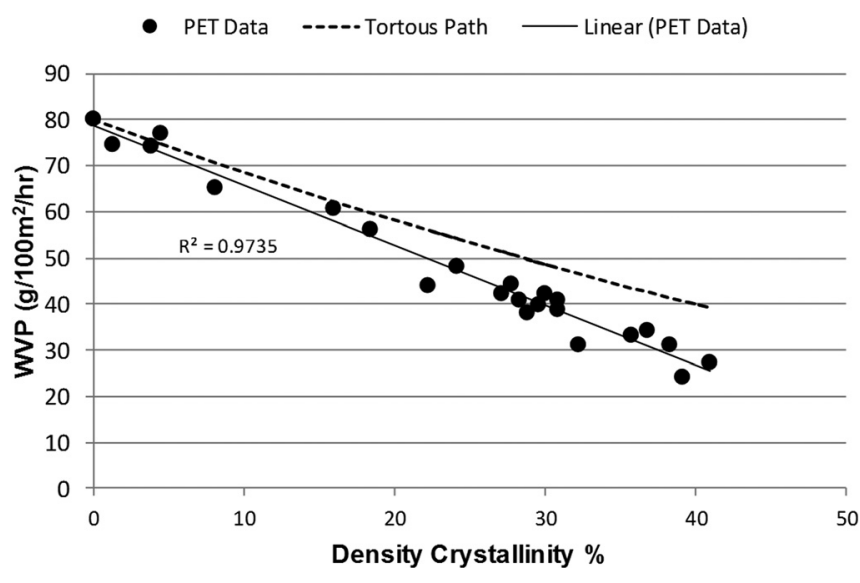

FIG. 10. Water Vapour Permeability of PET versus Density CrystallinityData from Lasoski and Cobbs. ${ }^{23}$

copolyesters based on ethylene terephthalate. These authors have reported that, for PET and copolymers of ethylene terephthalate, the crystallinity obtained from density measurements was not equal to the crystallinity obtained from DSC measurements when the samples were prepared by cold crystallisation. In fact, their data show a very significant difference between the two measurements: the ratio of density crystallinity to DSC crystallinity was found to be around 0.75 . The discrepancy between density crystallinity and DSC crystallinity was explained in terms of de-densification of the amorphous phase. This was reported to be a characteristic of cold crystallisation but not of melt crystallisation.

Returning to the data of Lasoski and Cobbs, ${ }^{23}$ it is apparent that their PET films for permeability measurement were prepared by cold crystallisation and crystallinity was determined by density measurements. In Figure 11, the density crystallinity data of Lasoski and Cobbs has been converted to DSC crystallinity data by dividing by 0.75 . The conversion factor of 0.75 is taken directly from the experimental results of Polyakova et $a .^{24}$ It is seen that the data fit the tortuous path model, with a regression coefficient, $\mathrm{R}^{2}$, of 97 .

Finally, in Figure 12, the normalised water vapour permeability data for both PLA and PET are plotted as a function of DSC crystallinity. They overlay each other and both

O PET Data - - - Tortuous Path

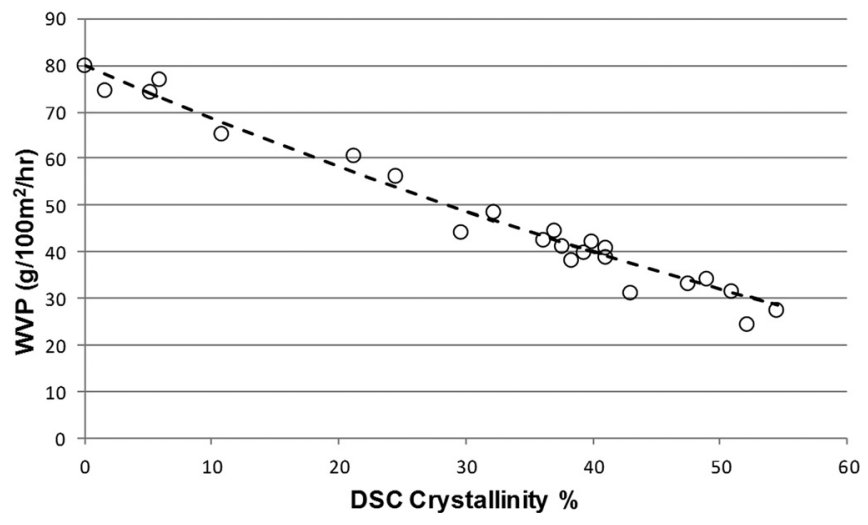

FIG. 11. Water Vapour Permeability of PET versus DSC CrystallinityData from Lasoski and Cobbs. ${ }^{23}$

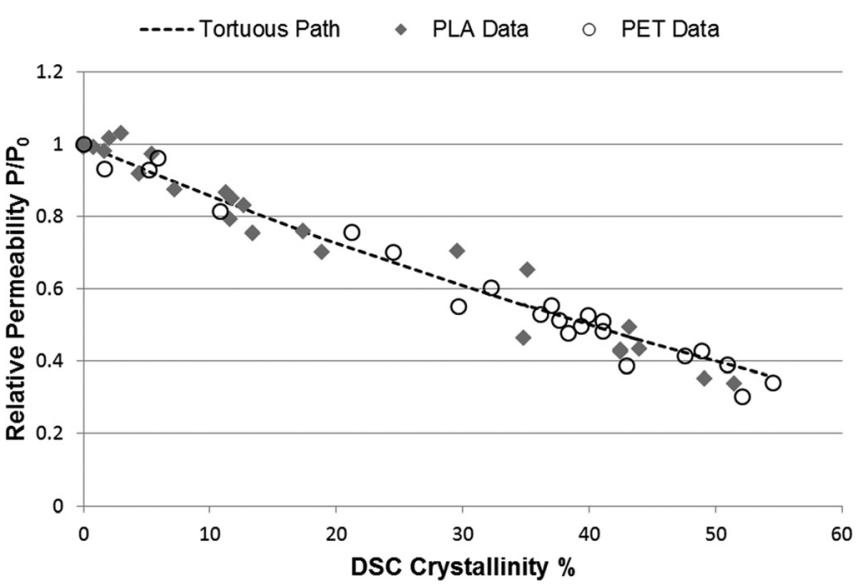

FIG. 12. Comparison of the Relative Water Vapour Permeability Data of PLA and PET and the Fit to the Tortuous Path Model.

fit the tortuous path model with an aspect ratio of one (Eq. (5)).

\section{CONCLUSIONS}

PLA films were prepared from three different grades of commercial PLA with different ratios of L-lactide and D-lactide to give a range of crystallinities from $0 \%$ to $50 \%$. Samples were produced by melt compounding followed by compression moulding and annealing at different temperatures and for different times to give the range of crystallinities required. Crystallinity was measured by DSC.

Water vapour transmission rates through the films were measured at $38{ }^{\circ} \mathrm{C}$ and at a relative humidity of $90 \%$. It was found that the measured values of WVTR decreased linearly with increasing crystallinity of the PLA from $0 \%$ to $50 \%$. The data showed a good fit to a linear trend line with a regression coefficient, $\mathrm{R}^{2}$, of 0.96 . This result was readily explained in terms of the effect of crystallinity on the solubility of water vapour in polymers: water is insoluble in the crystalline regions and so the solubility coefficient (S) of a semi-crystalline polymer is equal to the solubility coefficient of the amorphous fraction. The linear relationship predicts zero permeability when the crystallinity reaches about $78 \%$.

However, the data also gave a statistically significant fit $\left(\mathrm{R}^{2}\right.$ of 0.95$)$ to the "tortuous path" model, assuming that the spherulites are impermeable filler particles with an aspect ratio of 1 . This model predicts that the water vapour permeability reaches zero at $100 \%$ crystallinity, which is a more reasonable outcome.

It was found that the tortuous path model could also be used to explain published data (from Lasoski and Cobbs) on the water permeability of polyethylene terephthalate. First, it was necessary to convert density crystallinity to DSC crystallinity and then the PET data fitted the tortuous path model, with a regression coefficient, $\mathrm{R}^{2}$, of 97 .

\section{ACKNOWLEDGMENTS}

The authors are also grateful for funding for this work from the Engineering \& Physical Sciences Research Council (EPSRC) and PepsiCo International Ltd. 
${ }^{1}$ E. T. H. Vink, K. R. Rabago, D. A. Glassner, and P. R. Gruber, Polym. Degrad. Stab. 80, 403-419 (2003).

${ }^{2}$ D. Garlotta, J. Polym. Environ. 9, 63-84 (2001).

${ }^{3}$ R. Auras, B. Harte, and S. Selke, Macromol. Biosci. 4, 835-864 (2004).

${ }^{4} \mathrm{H}$. Tsuji and Y. Ikada, Polymer 36, 2709-2716 (1995).

${ }^{5}$ M. Yasuniwa, S. Tsubakihara, K. Iura, Y. Ono, Y. Dan, and K. Takahashi, Polymer 47, 7554-7563 (2006)

${ }^{6}$ P. Pan, B. Zhu, W. Kai, T. Dong, and Y. Inoue, Macromolecules 40, 6898-6905 (2007).

${ }^{7}$ P. Pan, B. Zhu, W. Kai, T. Dong, and Y. Inoue, Macromolecules 41, 4296-4304 (2008).

${ }^{8}$ A. S. Michaels, W. R. Vieth, and J. A. Barrie, J. Appl. Phys. 34, 1-12 (1963).

${ }^{9}$ A. S. Michaels, W. R. Vieth, and J. A. Barrie, J. Appl. Phys. 34, 13-20 (1963).

${ }^{10}$ M. Drieskens, R. Peeters, J. Mullens, D. Franco, P. J. Lemstra, and D. G. Hristova-Bogaerds, J. Polym. Sci. Pol. Phys. 47, 2247-2258 (2009).

${ }^{11}$ R. Shogren, J. Environ. Polym. Degrad. 5, 91-95 (1997).

${ }^{12}$ G. L. Siparsky, K. J. Voorhees, J. R. Dorgan, and K. Schilling, J. Environ. Polym. Degrad. 5, 125-136 (1997).
${ }^{13}$ H. Tsuji, R. Okino, H. Daimon, and K. Fujie, J. Appl. Polym. Sci. 99, 2245-2252 (2006).

${ }^{14} \mathrm{H}$. Tsuji and T. Tsuruno, Macromol. Mater. Eng. 295, 709-715 (2010).

${ }^{15}$ M. Cocca, M. L. Di Lorenzo, M. Malinconico, and V. Frezza, Eur. Polym. J. 47, 1073-1080 (2011).

${ }^{16}$ L. E. Nielsen, J. Macromol. Sci. A (Chem.) 1(5), 929-942 (1967).

${ }^{17}$ Z. Duan, N. L. Thomas, and W. Huang, J. Membr. Sci. 445, 112-118 (2013).

${ }^{18}$ N. L. Thomas, Prog. Org. Coat. 19, 101-121 (1991).

${ }^{19}$ W. J. Muizebelt and W. J. M. Heuvelsland, Polym. Mater. Sci. Eng. 53, 454-456 (1985).

${ }^{20}$ R. A. Auras, B. Harte, S. Selke, and R. Hernandez, J. Plast. Film Sheet 19, 123-134 (2003).

${ }^{21}$ J.-W. Rhim, A. K. Mohanty, S. P. Singh, and P. K. W. Ng, J. Appl. Polym. Sci. 101, 3736-3742 (2006).

${ }^{22}$ G. Choudalakis and A. D. Gotsis, Eur. Polym. J. 45, 967-984 (2009).

${ }^{23}$ S. W. Lasoski and W. H. Cobbs, J. Polym. Sci. 36, 21-33 (1959).

${ }^{24}$ A. Polyakova, E. V. Stephanov, D. Sekelik, D. A. Schiraldi, A. Hiltner, and E. Baer, J. Polym. Sci. Pol. Phys. 39, 1911-1919 (2001). 